\title{
Concepção de currículo em Dermeval Saviani e suas relações com a categoria marxista de liberdade
}

Carolina Nozella Gama(a)

Newton Duarte ${ }^{(b)}$

Gama CN, Duarte N. The curriculum conception in Dermeval Saviani and its relations with the marxist category of freedom. Interface (Botucatu). 2017; 21(62):521-30.

Dermeval Saviani analyzes the educational work using the marxist approach, articulating issues relating to philosophy and history of education, educational policy and educational theory, providing inputs for coping with the emptying process suffered by the the school curriculum. From the contribution of Saviani and others regarding the construction of the historicalcritical pedagogy, some curricular principles for the theachig content selection can be formulated. As an example, the question of the classics is pointed out by Saviani as a reference for the selection of school subjects. The category of freedom is understood following the marxist tradition in a way opposed to the liberal-bourgeois point of view based on the historical analysis of the construction of sociability and culture using work as foundation. This historical perspective gives meaning to the ideas proposed by Saviani regarding knowledge, human education and school curriculum.

Keywords: Curriculum. Dermeval Saviani. Historical-critical pedagogy. Freedom. Marxism.
Dermeval Saviani analisa o trabalho educativo pelo enfoque marxista, articulando questões relativas à filosofia e história da educação, política educacional e teoria pedagógica, fornecendo sustentação para o enfrentamento do esvaziamento do currículo escolar. A partir da contribuição desse educador e de outros que a ele se somam, na construção da pedagogia histórico-crítica, alguns princípios curriculares podem ser formulados para a seleção dos conteúdos do ensino. Um exemplo é a questão dos clássicos, que Saviani aponta como referência para a seleção dos conteúdos escolares. A categoria de liberdade é compreendida, pela tradição marxista, de maneira contraposta à visão liberal-burguesa e tem como fundamento a análise histórica da construção da sociabilidade e da cultura a partir da atividade de trabalho. É esta perspectiva histórica que dá sentido às ideias defendidas por Saviani sobre o conhecimento, a formação humana e o currículo escolar.

Palavras-chave: Currículo. Dermeval Saviani. Pedagogia histórico-crítica. Liberdade. Marxismo.

\footnotetext{
(a) Centro de Educação, Universidade Federal de Alagoas. Campus A. C. Simões, Avenida Lourival Melo Mota, $\mathrm{s} / \mathrm{n}$, Tabuleiro dos Martins. Maceió, AL, Brasil. 57072-970. carolina.gama@ cedu.ufal.br (b) Departamento de Psicologia da Educação, Universidade Estadual Paulista "Júlio de Mesquita Filho". Araraquara, SP, Brasil. newton@fclar.unesp.br
} 


\section{Introdução}

A concepção de currículo na obra de Dermeval Saviani indica possibilidades reais para se pensar o currículo, visando o desenvolvimento da pedagogia histórico-crítica como uma concepção de formação humana na perspectiva da transição do capitalismo para o socialismo e, deste, para o comunismo. Nesse sentido, iniciamos esse artigo explicitando alguns princípios curriculares para a seleção dos conteúdos do ensino e para o trato com o conhecimento. Na sequência, discutimos como esses princípios articulam-se à teoria marxista da liberdade. Afinal, na sociedade capitalista o trabalho gera a anulação da liberdade do trabalhador, posto que este é obrigado, pelas condições objetivas de vida, a vender sua atividade para poder sobreviver. Ao mesmo tempo e contraditoriamente, o trabalho na sociedade capitalista é a fonte de enormes avanços em termos das possibilidades de construção de uma sociedade na qual os seres humanos possam viver e atuar de maneira livre e universal.

\section{Princípios curriculares à luz da pedagogia histórico-crítica}

Conforme Saviani1, "[...] currículo é o conjunto das atividades nucleares desenvolvidas pela escola." (p. 16). Trata-se das atividades essenciais que a escola não pode deixar de desenvolver, sob pena de perder a sua especificidade. O processo de "seleção do conhecimento" a ser incorporado ao currículo não deve se dar de maneira aleatória, mas com base no que é necessário ao ser humano conhecer para enfrentar os problemas que a realidade apresenta ${ }^{2}$. A problematização da realidade pelo professor como parte do método da prática pedagógica é fundamental, pois a seleção do conhecimento que se vincula à definição dos objetivos de ensino implica definir "prioridades" (distinguir o que é principal do que é que secundário), o que é ditado "[...] pelas condições da situação existencial concreta em que vive o homem."2 (p. 39).

Malanchen ${ }^{3}$ explica que a escola precisa garantir a socialização dos conhecimentos "científicos, filosóficos e artísticos", devendo permitir a superação do conhecimento espontâneo pelo conhecimento elaborado ${ }^{1}$. Guiada pelas formulações do Coletivo de Autores ${ }^{4}$ acerca de princípios curriculares, a tese de Gama ${ }^{5}$ explicita como tais princípios podem ser aprofundados a partir das formulações de Saviani. Três princípios para a "seleção dos conteúdos de ensino" - Relevância social do conteúdo; Adequação às possibilidades sociocognitivas do aluno e Objetividade e enfoque científico do conhecimento - podem ser destacados; pois estes possuem relação intrínseca entre si e com os princípios metodológicos para o trato com o conhecimento (da síncrese à síntese; simultaneidade dos conteúdos enquanto dados da realidade; ampliação da complexidade do conhecimento e Provisoriedade e historicidade dos conhecimentos) $)^{5}$.

No que tange ao princípio da Relevância social do conteúdo, o Coletivo de Autores ${ }^{4}$ explica que o conteúdo a ser tratado "[...] deverá estar vinculado à explicação da realidade social concreta e oferecer subsídios para a compreensão dos determinantes sócio-históricos do aluno, particularmente a sua condição de classe social." (p. 31). Saviani ${ }^{6}$ permite-nos complementar tal assertiva ao ressaltar que, sendo o saber um meio de produção, sua apropriação contraria a lógica do capital baseada na propriedade privada desses meios. Defendemos que o conhecimento sistematizado seja apropriado pelos trabalhadores na escola, pois ele pode se converter em força material, permitindo o desenvolvimento da compreensão acerca das relações sociais de produção ${ }^{7-8}$.

Nessa perspectiva, a "[...] organização curricular dos vários níveis e modalidades de ensino [...] deverá tomar como referência a forma de organização da sociedade atual, assegurando sua plena compreensão por parte de todos os educandos."9 (p. 32). A noção de "clássico" orienta a definição dos currículos escolares, fornecendo "[...] um critério para se distinguir, na educação, o que é principal do que é secundário; o essencial do acessório; o que é duradouro do que é efêmero; o que indica tendências estruturais daquilo que se reduz à esfera conjuntural."10 (p. 27-28).

[...] clássico é aquilo que resistiu ao tempo, tendo uma validade que extrapola o momento em que foi formulado. Define-se, pois, pelas noções de permanência e referência. Uma vez que, mesmo nascendo em determinadas conjunturas históricas, capta questões nucleares que 
dizem respeito à própria identidade do homem como um ser que se desenvolve historicamente, o clássico permanece como referência para as gerações seguintes que se empenham em se apropriar das objetivações humanas produzidas ao longo do tempo. ${ }^{10}$ (p. 16).

A noção de clássico é um importante critério para guiar a seleção dos conhecimentos artísticos, filosóficos e científicos que devem ser abordados na escola. Trata-se de priorizar os conhecimentos que carregam a universalidade humana. Referimo-nos aos conhecimentos que possibilitam a relação entre os seres humanos e a totalidade da cultura, servindo de referência para que as novas gerações se apropriem do que foi produzido ao longo da história social.

Outro princípio é o da adequação dos conhecimentos às possibilidades sociocognitivas do aluno. Ao discutir a questão dos saberes do ponto de vista da forma "sofia" e da forma "episteme", Saviani8 esclarece que essas formas atravessam, indistintamente, os diferentes tipos de saber, ainda que com ênfases diferenciadas. As atitudes, à medida que se configuram como saber, implicam necessariamente certo grau de sistematização, assim como a experiência de vida tem um peso que não pode ser desconsiderado na forma como se constroem os saberes específicos ${ }^{8}$. Nesse sentido, " $[\ldots .$.$] o currículo$ escolar deve dispor, de forma que viabilize a sua assimilação pelos alunos, o conjunto de objetivações humanas [...]." O professor, por sua vez, "[...] ao lidar com o aluno concreto, precisará ter o domínio dessas objetivações para realizar aquela colaboração original do adulto para com a criança de que falava Vigotski."11 (p. 49). Isso significa dosar e sequenciar os conteúdos ao longo do tempo-espaço, tendo em vista atuar na zona de desenvolvimento iminente do aluno, considerando suas possibilidades e necessidades como sujeito histórico.

É neste âmbito que se situa o problema do conhecimento sistematizado [...]. Esse conhecimento sistematizado pode não ser do interesse do aluno empírico, ou seja, o aluno, em termos imediatos, pode não ter interesse no domínio desse conhecimento; mas ele corresponde diretamente aos interesses do aluno concreto, pois enquanto síntese das relações sociais, o aluno está situado numa sociedade que põe a exigência do domínio deste tipo de conhecimento $^{12}$. (p. 45)

Portanto, devemos considerar o aluno concreto. Como apontam os estudos no campo da psicologia histórico-cultural, há que se tratar o conhecimento tendo em vista o desenvolvimento do aluno, o que se faz incidindo sobre a zona de desenvolvimento iminente. Tal questão se traduz na afirmação de Vigotski ${ }^{13}$ de que o bom ensino é aquele que antecede o desenvolvimento. Do mesmo modo que é contraproducente o ensino que exige o que está além dos limites da zona de desenvolvimento iminente, também é inócuo, em termos de desenvolvimento psíquico, o ensino que se limita ao que o aluno consegue fazer por si mesmo.

Outro relevante princípio curricular é o da objetividade e enfoque científico do conhecimento. Essa premissa é abordada por Saviani' ${ }^{1}$ que salienta ser necessário superar a falsa afirmativa positivista que identifica objetividade e neutralidade e esclarece que a questão da neutralidade é uma questão ideológica que diz respeito ao caráter interessado ou não do conhecimento, enquanto a objetividade é uma questão gnosiológica, que diz respeito à correspondência ou não do conhecimento com a realidade a que se refere.

O fato do conhecimento ser sempre interessado, sendo a neutralidade impossível, não significa a impossibilidade da objetividade. Afinal, "[...] dizer que determinado conhecimento é universal significa dizer que ele é objetivo, isto é, se ele expressa as leis que regem a existência de determinado fenômeno, trata-se de algo cuja validade é universal."1 (p. 57-8). Buscar a objetividade do conhecimento corresponde à explicitação das múltiplas determinações que produzem e explicam os fatos. Por isso, é preciso identificar o aspecto gnosiológico (centrado no conhecimento e na objetividade) e o aspecto ideológico (expressão dos interesses, na subjetividade), uma vez que os seres humanos são impelidos a conhecer em função da busca pelos meios que atendam às suas necessidades e satisfaçam suas carências. Assim, a historicização é a forma de resgatar a objetividade e a universalidade do saber; não por acaso a historicidade do conhecimento é um dos princípios metodológicos a serem considerados no trato com o conhecimento, como veremos mais adiante. 
O conceito de saber objetivo utilizado por Saviani é fundamental para a discussão do currículo na perspectiva histórico-crítica, pois indica que há que se tratar na escola de um conjunto de conhecimentos sistematizados que a humanidade acumulou acerca da realidade ao longo da história; há que se ter um enfoque científico, e não do senso comum, do conhecimento. Tal perspectiva contrapõe-se às concepções curriculares relativistas de cunho pós-moderno, que negam a possibilidade de apreensão do real para além das aparências, pautando-se no improviso e rejeitando o critério de maior ou menor grau de fidedignidade dos conhecimentos acerca da realidade ${ }^{3}$.

Considerando que "para existir a escola não basta a existência do saber sistematizado", sendo necessário viabilizar as condições de sua transmissão e apropriação, o que implica "dosá-lo e sequenciá-lo de modo que a criança passe gradativamente do seu não domínio ao seu domínio"1 ( $p$. 18), os "[...] princípios da seleção do conteúdo remetem à necessidade de organizá-lo e sistematizálo fundamentado em alguns princípios metodológicos, vinculados à forma como serão tratados no currículo, bem como à lógica com que serão apresentados aos alunos ${ }^{4 "}$ (p. 31).

Iniciemos pelo princípio da síncrese à síntese ou da aparência à essência, que pode ser compreendido quando Saviani ${ }^{1}$ destaca que o papel da escola é possibilitar, por meio do acesso à cultura erudita, a " [...] apropriação de novas formas por meio das quais se podem expressar os próprios conteúdos do saber popular" (p. 22). Não se trata de excluir ou negar o saber popular, mas superá-lo e torná-lo rico em novas determinações, atingindo-se no ponto de chegada do trabalho educativo aquilo que não estava posto no ponto de partida. Trata-se de estabelecer um movimento dialético entre o saber espontâneo e o saber sistematizado, entre a cultura popular e a cultura erudita, de forma que a ação escolar permita que se acrescentem novas determinações que possam enriquecer as anteriores; o saber espontâneo, baseado na experiência de vida, e a cultura popular são a base que torna possível a elaboração do saber e, consequentemente, a cultura erudita. Destarte, o acesso à cultura erudita possibilita a apropriação de novas formas pelas quais se pode expressar os próprios conteúdos do saber popular.

Com isso, Saviani ${ }^{6}$ defende ser necessário combater tanto o rebaixamento vulgar da cultura para as massas como a sofisticação esterilizadora da cultura das elites, que coexistem nesse momento conservador, transcendendo a "cultura superior" (ciências, letras, artes e filosofia) como privilégio restrito a pequenos grupos da elite. É tarefa fundamental da escola viabilizar o acesso ao conhecimento sistematizado, pois o "[...] conhecimento de senso comum se desenvolve e é adquirido independentemente da escola."8 (p. 1-2). Dessa forma, contribui-se para a compreensão dialética da realidade, de modo a articular o singular - o trabalho pedagógico desenvolvido nas escolas (trato com o conhecimento, organização escolar) - com o geral - a transformação da realidade regida pelo capital (o projeto histórico-socialista).

Outro princípio é o da simultaneidade dos conteúdos como dados da realidade. Trata-se de buscar assegurar na organização curricular a visão de totalidade, que carrega o particular e o universal, demonstrando as relações e nexos entre os diferentes conteúdos, ou seja, trata-se de, por meio da socialização dos conteúdos das diferentes áreas do conhecimento, permitir ao aluno que aprofunde sua compreensão acerca da realidade. Considerando que, para produzir materialmente, o ser humano necessita antecipar em ideias os objetivos da ação, é necessário impulsionar os alunos a representarem mentalmente os objetivos reais, o que inclui o aspecto de conhecimento das propriedades do mundo real (ciência), de valorização (ética) e de simbolização (arte) na produção de ideias, conceitos, valores, símbolos, hábitos, atitudes e habilidades ${ }^{8}$.

Assim empreende-se um movimento que vai "[...] da síncrese ('a visão caótica do todo') à síntese ('uma rica totalidade de determinações e de relações numerosas') pela mediação da análise ('as abstrações e determinações mais simples') [...]", o que constitui uma "[...] orientação segura tanto para o processo de descoberta de novos conhecimentos (o método científico) como para o processo de transmissão-assimilação de conhecimentos (o método de ensino)."14 (p. 74). Esse percurso orienta a organização e sistematização lógica e metodológica do conhecimento por dentro de uma unidade de ensino, bem como de uma etapa ou ano escolar, remetendo ao princípio seguinte.

A ampliação da complexidade do conhecimento, que parte do entendimento de que a apropriação de dado conhecimento não se dá de forma linear, em uma "única dose", mas por meio de sucessivas 
aproximações. Em um processo no qual vão se ampliando as referências acerca do objeto (apreensão das múltiplas determinações), a representação do real no pensamento vai sendo produzida, ampliando-se e tornando-se cada vez mais fidedigna. Assim, o trato escolar com o conhecimento, embora requeira a sistematização de sequências dos conteúdos curriculares, não deve ser visto de maneira linear, na forma de etapas que se sucedem rigidamente e às quais não se retorna. O que mudaria de uma unidade de ensino ou de uma série para outra, além da incorporação de novos conteúdos, seria a ampliação das referências sobre aspectos da realidade já estudados que, dessa maneira, serão compreendidos pelos alunos de forma cada vez mais aprofundada e complexa.

De um período para o outro enriquecem-se as determinações acerca dos objetos estudados, incorporam-se ao saber escolar novos conhecimentos sobre esses objetos e também novos objetos das ciências, das artes e da filosofia, avançando-se na qualidade do conhecimento apropriado e objetivado. O currículo deverá traduzir essa organização dispondo o tempo, os agentes e os instrumentos necessários para que se alcance a aprendizagem¹.

Há outros textos em que Saviani ${ }^{6,7,15}$ trata da organização curricular e reforça a pertinência do princípio curricular da ampliação da complexidade do conhecimento. Ao examinar as contradições da educação burguesa, o autor propõe que a organização do sistema de ensino deva guiar-se pelo enfrentamento das contradições inerentes ao sistema capitalista, sendo três delas mais relacionadas à educação: contradição, homem e sociedade; homem e trabalho; homem e cultura ${ }^{15}$.

As considerações referentes ao princípio metodológico da ampliação da complexidade do conhecimento fornecem elementos para pensarmos a organização escolar, seja em termos de como organizar metodologicamente uma aula ou unidade de ensino, seja em termos de como organizar os níveis de ensino e o conhecimento ao longo dos anos escolares. Isso nos remete a outro princípio curricular: o da provisoriedade e historicidade dos conhecimentos.

Conforme o Coletivo de Autores ${ }^{4}$, "[...] é fundamental para o emprego desse princípio apresentar o conteúdo ao aluno, desenvolvendo a noção de historicidade, retraçando-o desde a sua gênese, para que ele se perceba como sujeito histórico." (p. 33). Sobre isso, à luz da problematização da questão escolar realizada por Gramsci em "Os intelectuais e a organização da cultura", em especial a passagem em que o autor tratou da centralidade que a cultura greco-romana tinha na escola tradicional, traduzida no cultivo das línguas latina e grega e das respectivas literaturas e histórias políticas, Saviani ${ }^{16}$ argumenta que a História seria exatamente essa matéria que deve ocupar o lugar central no novo princípio educativo da escola do nosso tempo.

Conforme Taffarel et al. ${ }^{17}$, trata-se de assumir a história como matriz científica, de modo que a organização dos conteúdos curriculares oriente-se pelo princípio da radical historicidade do homem, organizando-se "[...] em torno do mesmo conteúdo, a própria história dos homens, identificado como o caminho comum para formar indivíduos plenamente desenvolvidos." ${ }^{16}$ (p. 129). Afinal, o presente tem uma história enraizada no passado, ao passo que também contém elementos que projetam o futuro. Dessa maneira, é impossível compreender com radicalidade o presente sem compreender as suas raízes, o que implica o estudo de sua gênese ${ }^{18}$.

Nessa perspectiva, é imprescindível para o trato com conhecimento abordá-lo na sua historicidade, como produto da ação humana concretizada em um dado momento histórico. Ademais, a história do desenvolvimento dos conhecimentos produzidos pela humanidade fornece pistas importantes para sua organização, sistematização e sequenciamento lógico e metodológico. Esse princípio não deve, porém, ser entendido de maneira mecânica, como se o estudo de cada tópico dos conteúdos escolares devesse necessariamente ser precedido de uma exposição sobre sua gênese histórica ou a sequência de ensino devesse necessariamente reproduzir o percurso histórico de determinado conhecimento. Há aqui a necessidade de se considerar a dialética entre o lógico e o histórico, isto é, entre um determinado fenômeno em sua forma mais desenvolvida e seu processo de desenvolvimento ${ }^{19}$.

Os princípios curriculares expostos articulam-se, mas não devem ser tomados isoladamente ou como receituários a serem aplicados de forma descontextualizada; pois, ao contrário, têm função de orientar a definição e organização do currículo, bem como o trabalho educativo, que articula o trabalho individual em torno de um projeto coletivo de formação. 


\section{Relações entre o currículo e a categoria de liberdade na tradição marxista}

Em estudo recente, Duarte ${ }^{20}$, pela perspectiva da pedagogia histórico-crítica, estabelece relações entre os conhecimentos escolares e a categoria de liberdade, tomando como referência a abordagem dessa categoria na tradição marxista. Ultrapassaria os limites e os propósitos desse artigo uma análise dos momentos em que a categoria de liberdade se apresenta na obra de Dermeval Saviani. O enfoque aqui adotado reduz-se apenas aos aspectos mais diretamente ligados à concepção de currículo.

Como já foi assinalado neste artigo, a concepção marxista de conhecimento ocupa lugar central na teoria pedagógica histórico-crítica, partindo-se da definição da especificidade escolar, que reside na socialização do saber sistematizado. Em texto intitulado "Marxismo, Educação e Pedagogia", Saviani ${ }^{21}$ distingue a concepção marxista de conhecimento tanto da visão moderna quanto da pós-moderna:

Vê-se, pois, que estamos diante de uma concepção claramente realista, em termos ontológicos, e objetivista, em termos gnosiológicos. Assenta-se, portanto, em duas premissas fundamentais: 1. As coisas existem independentemente do pensamento, com o corolário: é a realidade que determina as ideias e não o contrário; 2 . A realidade é cognoscível, com o corolário: o ato de conhecer é criativo não enquanto produção do próprio objeto de conhecimento, mas enquanto produção das categorias que permitam a reprodução, em pensamento, do objeto que se busca conhecer. (p. 63)

Além disso, o autor defende que o aspecto gnosiológico e o ideológico do conhecimento " $[. .$. não se confundem, não se excluem mutuamente e não se negam reciprocamente." 21 (p. 66). Assim, a concepção marxista de conhecimento não se contrapõe à exigência de objetividade, mas, ao contrário, procura levá-la às últimas consequências.

É nesse sentido que, no marxismo, unem-se o materialismo, a dialética e o historicismo, formando uma concepção de mundo que dá sentido à defesa, pela pedagogia histórico-crítica, da socialização dos conhecimentos científicos, artísticos e filosóficos em suas formas mais desenvolvidas ${ }^{22}$.

Nessa direção, Saviani ${ }^{21}$ articula explicitamente a construção da pedagogia histórico-crítica ao projeto socialista:

Penso que a tarefa da construção de uma pedagogia inspirada no marxismo implica a apreensão da concepção de fundo [de ordem ontológica, epistemológica e metodológica] que caracteriza o materialismo histórico. Imbuído dessa concepção, trata-se de penetrar no interior dos processos pedagógicos, reconstruindo suas características objetivas e formulando as diretrizes pedagógicas que possibilitarão a reorganização do trabalho educativo sob os aspectos das finalidades e objetivos da educação, das instituições formadoras, dos agentes educativos, dos conteúdos curriculares e dos procedimentos pedagógico-didáticos que movimentarão um novo éthos educativo voltado à construção de uma nova sociedade, uma nova cultura, um novo homem. (p. 81)

A questão da liberdade está, portanto, no centro desse processo de construção de uma pedagogia inspirada no marxismo, necessariamente articulada à construção de uma nova sociedade, uma nova cultura e um novo ser humano.

Trata-se, primeiramente, da afirmação de que a humanidade não está definitivamente aprisionada ao capitalismo. Se essa sociedade colocou em movimento forças produtivas desconhecidas pelas formações sociais precedentes, as relações capitalistas de produção tornaram-se um obstáculo não só ao desenvolvimento dessas forças produtivas como também ao seu direcionamento em prol de necessidades humanizadoras e de formas sustentáveis de relacionamento entre sociedade e natureza.

É importante também reafirmar que a liberdade está no centro do projeto de uma sociedade socialista. Os problemas ocorridos nos países que, no século XX, tentaram construir o socialismo acabaram sendo usados pela ideologia liberal como argumento para difusão da distorcida visão de que o socialismo se oporia ao princípio da liberdade e que o capitalismo estaria pautado nesse princípio. A 
visão liberal, além de se restringir a uma concepção formal de liberdade, desconsidera que o processo de reprodução do capital não só foge ao controle dos seres humanos como se impõe de maneira fetichista, como um ser sobre-humano que possui vida própria e não se detém diante de qualquer obstáculo de natureza ética, jurídica, política, ambiental, cultural, etc.

Como pode ser o baluarte da liberdade uma sociedade que impõe a pobreza à maioria da humanidade em nome da opulência de uma minoria, que se vê impotente perante o problema da destruição dos recursos naturais causada por uma produção de mercadorias pautada no princípio da obsolescência programada, que não se mostra capaz de oferecer às novas gerações alternativas de futuro que deem sentido à vida para além do hedonismo imediatista que reduz tudo ao aqui e agora? O socialismo, diversamente, afirma que a humanidade é livre para redirecionar as forças produtivas, colocando-as a serviço da produção de necessidades verdadeiramente humanizadoras e fazendo do trabalho uma atividade que, ao invés de escravizar as pessoas em decorrência da venda da força de trabalho, seja uma das principais formas de livre desenvolvimento das capacidades e das necessidades humanas.

Quando a pedagogia histórico-crítica postula que o trabalho seja o princípio educativo, não está tomando como referência o trabalho assalariado do qual o capital extrai a mais-valia, mas sim a importância do trabalho para a construção histórica das possibilidades objetivas e subjetivas de liberdade para a humanidade ${ }^{22}$.

Foi a partir da forma primeira e fundamental de atividade de trabalho, ou seja, a transformação da natureza com vistas à satisfação das necessidades humanas, que se desenvolveu a dialética entre os processos de objetivação e de apropriação, que constituem a dinâmica fundamental de relacionamento entre cada indivíduo e a cultura historicamente construída ${ }^{23}$. A partir dessa forma básica de trabalho, indispensável a todo tipo de sociedade, surgiram e desenvolveram-se novas necessidades que geraram esferas mais elevadas de objetivação, chegando-se às formas mais desenvolvidas e complexas que são a ciência, a arte e a filosofia.

A defesa do trabalho escolar com os clássicos da ciência, da arte e da filosofia não denota desconsiderar que eles refletem as contradições que marcam o desenvolvimento humano, até o presente caracterizado pela luta de classes. A seleção dos conteúdos escolares não é neutra, mesmo quando realizada a partir de concepções que pretendam impor à ação pedagógica uma suposta neutralidade política. A pedagogia histórico-crítica não esconde seu posicionamento político, do qual deriva sua defesa de um sistema público de ensino que assegure a socialização do saber sistematizado. Os arautos do liberalismo não defendem, de fato, a plena liberdade para todos, mas sim apenas o tipo de liberdade que permita à burguesia continuar a subjugar o restante da humanidade à lógica do capitalismo contemporâneo, dominado pela forma mais destrutiva de capital, que é o capital financeiro.

O conhecimento por si só não liberta o ser humano: o que o liberta é a prática social. Da mesma forma, não há qualquer resquício, na obra de Dermeval Saviani, da ideia de que a socialização do saber sistematizado pela educação escolar promoveria, por si só, a libertação das pessoas. Isso seria idealismo e se a pedagogia histórico-crítica acreditasse nessa ideia, seu nome estaria errado, pois ela não estaria historicizando o conhecimento, nem abordando de maneira crítica as relações entre conhecimento e transformação social. As teorias situadas no campo da esquerda, porém, que não atribuem ao conhecimento qualquer papel relevante no processo de superação da sociedade capitalista, também padecem do mesmo idealismo que julgam negar, pois destituem a revolução da necessária fundamentação no conhecimento objetivo da realidade social e desconsideram as complexas mediações que unem os mais abstratos conhecimentos à prática social em sua totalidade.

Como já foi explicitado neste artigo, para a pedagogia histórico-crítica, o currículo escolar é uma unidade de conteúdo e forma. Assim, as relações entre a concepção de currículo na obra de Dermeval Saviani e a categoria de liberdade na tradição marxista mostram-se também nas ideias que esse educador defende acerca das formas de se ensinar e se aprender o saber sistematizado. Esse é um ponto, aliás, no qual a pedagogia histórico-crítica tem sido injustamente alvo de muitas acusações, especialmente dos educadores alinhados às "pedagogias do aprender a aprender" ${ }^{24}$, que tendem a considerar que a pedagogia histórico-crítica opta pelas formas tradicionais de ensino em detrimento de formas que valorizam a liberdade do aluno. Não é o caso de se retomar aqui as análises 
que os educadores da pedagogia histórico-crítica já fizeram sobre os limites e as inconsistências das "pedagogias do aprender a aprender" 24 , pois nosso foco volta-se para o fato de que Saviani, ao abordar a questão das formas de se ensinar e aprender, mantém-se coerentemente na linha do tratamento dado pelos clássicos do marxismo à categoria de liberdade.

Um exemplo dessa questão abordada, extraído do texto "Sobre a natureza e a especificidade da educação", capítulo do livro "Pedagogia histórico-crítica: primeiras aproximações"1 , refere-se ao caráter aparentemente paradoxal da condição de aprendiz. Nesse texto, Saviani, ao defender que a formação de automatismos é condição para liberdade, dá como exemplo o processo pelo qual uma pessoa aprende a dirigir um automóvel. De início, cada um dos movimentos, isto é, das operações que formam a ação de dirigir o automóvel, deve ser aprendido pelo iniciante, o que exige grande atenção, esforço e repetição, sem o qual a pessoa não adquire o automatismo que lhe permitirá conduzir o automóvel com destreza, segurança e autonomia. Antes de alcançar esse nível, o aprendiz estará prisioneiro do esforço necessário à realização de cada movimento.

A concentração da atenção exigida para realizar a sincronia desses movimentos absorve todas as energias. Por isso o aprendiz não é livre ao dirigir. No limite, eu diria mesmo que ele é escravo dos atos que tem que praticar. Ele não os domina, mas, ao contrário, é dominado por eles. A liberdade só será atingida quando os atos forem dominados. E isso ocorre no momento em que os mecanismos forem fixados. Portanto, por paradoxal que pareça, é exatamente quando se atinge o nível em que os atos são praticados automaticamente que se ganha condições de se exercer, com liberdade, a atividade que compreende os referidos atos. Então, a atenção liberta-se, não sendo mais necessário tematizar cada ato. Nesse momento, é possível não apenas dirigir livremente, mas também ser criativo no exercício dessa atividade. E só se chega a esse ponto quando o processo de aprendizagem, enquanto tal, completouse. Por isso, é possível afirmar que o aprendiz, no exercício daquela atividade que é o objeto da aprendizagem, nunca é livre. Quando ele for capaz de exercitá-la livremente, nesse exato momento ele deixou de ser aprendiz. As considerações supra podem ser aplicadas em outros domínios, como, por exemplo, aprender a tocar um instrumento musical etc ${ }^{1}$. (p. 19-20)

O caráter aparentemente paradoxal da condição de aprendiz está no fato de que, para alcançar a liberdade na realização de um determinado tipo de atividade, o indivíduo precisa inicialmente ser destituído de sua liberdade, submetendo-se aos processos que ainda não domina quando tem início a aprendizagem; mas sua liberdade será reconquistada em um nível mais elevado, quando alcançar a autonomia na realização daquela atividade, por meio do domínio das operações por ela requeridas. Esse processo de conquista da liberdade, pela mediação da subordinação inicial àquilo que se pretende dominar, está presente na atividade humana desde a mais primitiva produção de instrumentos. Todos os clássicos do marxismo abordaram, de uma forma ou de outra, o caminho pelo qual o ser humano avançou no domínio da natureza, conhecendo e respeitando sua processualidade objetiva para colocar essa processualidade a serviço da satisfação das necessidades humanas, o que foi chamado por Hegel como a astúcia da razão 25 .

Concluindo, podemos afirmar que o currículo na concepção histórico-crítica tem como objeto o desenvolvimento das funções psicológicas superiores dos estudantes nas suas máximas possibilidades dentro das condições históricas atuais, o que, nas palavras de Saviani, significa produzir, em cada indivíduo singular, a humanidade que é produzida, histórica e coletivamente, pelo conjunto dos homens. Tal processo implica não perder de vista a noção do todo, em especial, a unidade conteúdo-forma, pois alterar o conteúdo que é ensinado nas escolas, avançando na socialização do saber sistematizado, perpassa pela alteração da forma de organização escolar. Assim, podemos dizer que é impossível pensar a alteração da organização escolar sem que haja a alteração do conteúdo que é tratado na escola.

Esperamos ter evidenciado que tratar do currículo na perspectiva histórico-crítica articula-se à questão da liberdade, que está no cerne do processo de construção de uma nova sociedade, uma nova cultura e um novo ser humano. 


\section{Colaboradores}

Carolina Nosella Gama e Newton Duarte participaram, igualmente, de todas as etapas de elaboração do artigo.

\section{Referências}

1. Saviani D. Pedagogia histórico-crítica: primeiras aproximações. 10a ed. Campinas: Autores Associados; 2008.

2. Saviani D. Educação: do senso comum à consciência filosófica. 15a ed. Campinas: Autores Associados; 2004.

3. Malanchen J. A pedagogia histórico-crítica e o currículo: para além do multiculturalismo das políticas curriculares nacionais [tese]. Araraquara (SP): Universidade Estadual Paulista; 2014.

4. Coletivo de Autores. Metodologia do ensino da educação física. São Paulo: Cortez; 1992.

5. Gama CN. Princípios curriculares à luz da pedagogia histórico-crítica: as contribuições da obra de Dermeval Saviani [tese]. Salvador (BA): Universidade Federal da Bahia; 2015.

6. Saviani D. Educação socialista, pedagogia histórico-crítica e os desafios da sociedade de classes. In: Saviani D, Lombardi JC, organizadores. Marxismo e educação: debates contemporâneos. Campinas: Autores Associados, HISTEDBR; 2008. p. 223-74.

7. Saviani D. Choque teórico da politecnia. Trab Educ Saude. 2003; 1(1):131-52.

8. Saviani D. Educação escolar, currículo e sociedade: o problema da base nacional comum curricular. Movimento. 2016; 3(4):54-84.

9. Saviani D. Ciência e educação na sociedade contemporânea: desafios a partir da pedagogia histórico-crítica. Rev Faz Cienc. 2010; 12(16):13-36.

10. Saviani D. Importância do conceito de "clássico" para a pedagogia. In: Teixeira Júnior A, organizador. Marx está vivo! Maceió: [s.ed]; 2010. p. 15-28.

11. Saviani D. Perspectiva marxiana do problema subjetividade-intersubjetividade. In: Giolo J. Conferência proferida no I Seminário Internacional sobre Filosofia e Educação. Esp Ped. 2003; 10:77-97.

12. Saviani D. Marxismo e educação. Principios. 2006; (14):37-45.

13. Vigotski LS. Aprendizagem e desenvolvimento intelectual na idade escolar. In: Vigotski LS, Leontiev NA, Luria AR. Linguagem, desenvolvimento e aprendizagem. São Paulo: Ícone, Editora USP; 1988. p.103-17.

14. Saviani D. Escola e democracia. 42a ed. Campinas: Autores Associados; 2012.

15. Saviani D. Trabalho e educação: fundamentos ontológicos e históricos. Rev Bras Educ. 2007; 12(34):152-80.

16. Saviani D. Pedagogia: o espaço da educação na universidade. Cad Pesqui. 2007; 37(130):99-134.

17. Taffarel CNZ, Santos Júnior C L, Escobar MO, organizadores. Cadernos didáticos sobre educação no campo. Salvador; 2009. p.183-203.

18. Saviani D. História das ideias pedagógicas no Brasil. Campinas: Autores Associados; 2007.

19. Duarte N. A anatomia do homem é a chave da anatomia do macaco: a dialética em Vigotski e em Marx e a questão do saber objetivo na educação escolar. Educ Soc. 2000; 21(71):79-115. doi: http://dx.doi.org/10.1590/S0101-73302000000200004. 
20. Duarte N. Relações entre conhecimento escolar e liberdade. Cad Pesqui. 2016; 46(159):78-102.

21. Saviani D. Marxismo, educação e pedagogia. In: Saviani D, Duarte N. Pedagogia histórico-crítica e luta de classes na educação escolar. Campinas: Autores Associados; 2012. p. 59-85.

22. Duarte N. A importância da concepção de mundo para a educação escolar: porque a pedagogia histórico-crítica não endossa o silêncio de Wittgenstein. Germinal Marxismo Educ Debate. 2015; 7(1):8-25.

23. Duarte N. A individualidade para si: contribuição à teoria histórico-crítica da formação do indivíduo. Campinas: Autores Associados; 2013.

24. Duarte N. As pedagogias do "aprender a aprender" e algumas ilusões da assim chamada sociedade do conhecimento. Rev Bras Educ. 2001; 18:35-40.

25. Lukács G. Para uma ontologia do ser social. São Paulo: Boitempo; 2012. v. 1.

Gama CN, Duarte N. Concepción de currículo en Dermeval Saviani y sus relaciones con la categoría marxista de libertad. Interface (Botucatu). 2017; 21(62):521-30.

Dermeval Saviani analiza el trabajo educativo por el enfoque marxista, articulando cuestiones relativas a la filosofía e historia de la educación, política educativa y teoría pedagógica, suministrando sustentación para el enfrentamiento del vaciado del currículo escolar. A partir de la contribución de ese educador y de otros que se suman a él, en la construcción de la pedagogía histórico-crítica, pueden formularse algunos principios curriculares para la selección de los contenidos de la enseñanza. Un ejemplo es la cuestión de los clásicos que Saviani señala como referencia para la selección de los contenidos escolares. La categoría de libertad es entendida, por la tradición marxista, de manera contrapuesta a la visión liberal burguesa y tiene como fundamento el análisis histórico de la construcción de la sociabilidad y de la cultura a partir de la actividad del trabajo. Es esa perspectiva histórica la que da sentido a las ideas defendidas por Saviani sobre el conocimiento, la formación humana y el currículo escolar.

Palabras clave: Currículo. Dermeval Saviani. Pedagogía histórico-crítica. Libertad. Marxismo. 